\title{
Lopinavir-Ritonavir Combination Induces Endoplasmic Reticulum Stress and Kills Urological Cancer Cells
}

\author{
KAZUKI OKUBO, MAKOTO ISONO, TAKAKO ASANO and AKINORI SATO \\ Department of Urology, National Defense Medical College, Tokorozawa, Japan
}

\begin{abstract}
Background/Aim: Induction of endoplasmic reticulum (ER) stress is a novel approach to cancer treatment. This study investigated the ability of the clinically feasible combination of the human immunodeficiency virus protease inhibitors lopinavir and ritonavir to induce ER stress killing urological cancer cells. Materials and Methods: Renal cancer cells (769-P, 786-O) and bladder cancer cells (UMUC-3, T-24) were used to investigate the ability of the combination to induce ER stress and its mechanism of action. Results: The combination inhibited the growth of both renal and bladder cancer cells synergistically by inducing ER stress. The combination-induced ER stress increased the expression of AMP-activated protein kinase and suppressed the mammalian target of rapamycin pathway. It also increased the expression of a tumor necrosis factor-related apoptosis-inducing ligand (TRAIL) receptor and thereby sensitized the cancer cells to TRAIL. Conclusion: The combination of lopinavir and ritonavir acts against urological cancer cells by inducing ER stress synergistically.
\end{abstract}

To date there is no curative treatment for patients with advanced urological malignances. Drug repositioning has emerged as a novel strategy for finding new anticancer agents: commonly used drugs are screened for their anticancer activity and clinically applied for cancer treatment $(1,2)$. This strategy lowers the cost of developing new cancer treatments and provides patients with promising new treatments quickly.

Ritonavir is an inhibitor of human immunodeficiency virus (HIV) protease used for the treatment of acquired

This article is freely accessible online.

Correspondence to: Akinori Sato, Department of Urology, National Defense Medical College, 3-2 Namiki, Tokorozawa, Saitama 3598513, Japan. E-mail: zenpaku@ndmc.ac.jp

Key Words: Lopinavir, ritonavir, endoplasmic reticulum stress, AMP-activated protein kinase, tumor necrosis factor-related apoptosis-inducing ligand, renal cancer, bladder cancer. immunodeficiency syndrome (AIDS). It inhibits cytochrome P450 and P-glycoprotein and has been used as a booster activating other antiviral drugs in clinical settings $(3,4)$. Lopinavir is also an HIV protease inhibitor, and a lopinavir/ritonavir formulation has been approved for the treatment of AIDS $(5,6)$.

Inducing endoplasmic reticulum (ER) stress is an emerging anticancer strategy (7), and lopinavir is one of the most potent ER stress inducers (8). In the present study, we tested our hypothesis that ritonavir would enhance the activity of lopinavir and that the combination would kill renal cancer cells and bladder cancer cells by inducing ER stress synergistically. Furthermore, we evaluated the combination's ability to increase the expression of tumor necrosis factor-related apoptosis-inducing ligand (TRAIL) receptor and thereby sensitize the cancer cells to TRAIL.

\section{Materials and Methods}

Cell culture. Human renal cancer cells (769-P, 786-O) and human bladder cancer cells (UMUC-3, T-24) were purchased from the American Type Culture Collection (Rockville, MD, USA). The cells were cultured in either Roswell Park Memorial Institute Medium 1640 (769-P and 786-O cells), Minimum Essential Medium (UMUC-3 cells), or McCoy's 5A medium (T-24 cells) containing $10 \%$ fetal bovine serum and $1.0 \%$ penicillin/streptomycin (Invitrogen, Carlsbad, CA, USA) at $37^{\circ} \mathrm{C}$ under $5 \% \mathrm{CO}_{2}$ in a humidified incubator.

Reagents and antibodies. Ritonavir purchased from Toronto Research Chemicals (North York, ON, Canada) and lopinavir purchased from Selleck (Houston, TX, USA) were dissolved in dimethyl sulfoxide. Cycloheximide purchased from Enzo Life Sciences (Farmingdale, NY, USA) was dissolved in distilled water. Human recombinant TRAIL purchased from R\&D Systems (Minneapolis, MN, USA) was dissolved in sterile phosphatebuffered saline (PBS) containing $0.1 \%$ bovine serum albumin. These solutions were stored at $-80^{\circ} \mathrm{C}$ or $-20^{\circ} \mathrm{C}$ until use. Primary antibodies for western blotting were used against the following: survivin and death receptor 5 (DR5) (Santa Cruz Biotechnology, Santa Cruz, CA, USA); cleaved poly(ADP-ribose) polymerase (PARP), S6 ribosomal protein, phosphorylated S6, eukaryotic translation initiation factor 4E-binding protein 1 (4EBP1), and 
endoplasmic reticulum resident protein 44 (ERp44 (Cell Signaling Technology, Danvers, MA, USA); glucose-regulated protein 78 (GRP78) and AMP-activated protein kinase (AMPK) (Proteintech, Rosemont, IL, USA); phorbol-12-myristate-13-acetate-induced protein 1 (NOXA; Abcam, Cambridge, UK), and actin (Millipore, Billerica, MA, USA). Horseradish peroxidase conjugated goat antimouse and goat anti-rabbit antibodies were purchased from GE Healthcare (Wauwatosa, WI, USA).

Assessing the combined effect of lopinavir and ritonavir on cell viability and colony formation. Cells were placed in 96-well culture plates $\left(5 \times 10^{3}\right.$ cells/well $) 1$ day before being treated for $48 \mathrm{~h}$ with 5 $40 \mu \mathrm{M}$ lopinavir with/without 5-40 $\mu \mathrm{M}$ ritonavir. Cell viability was then determined by MTS assay $(n=6)$. For colony formation assay, cells were placed in 6-well plates (300-500 cells/well) 1 day before treatment and cultured for $48 \mathrm{~h}$ with lopinavir $(40 \mu \mathrm{M}$ for $769-\mathrm{P}$ cells and $20 \mu \mathrm{M}$ for $\mathrm{T}-24$ cells $)$ with/without ritonavir $(10 \mu \mathrm{M}$ for 769-P cells and $40 \mu \mathrm{M}$ for T-24 cells). They were then given fresh media and allowed to grow for 1-2 weeks, after which they were then fixed with $100 \%$ methanol and stained with Giemsa's solution. The colonies were quantified by using the ImageJ-plugin ColonyArea (9) $(n=3)$.

Evaluating apoptosis induction by the lopinavir-ritonavir combination. Cells were placed in 12 -well culture plates $\left(1.0 \times 10^{5}\right.$ cells/well) 1 day before being cultured for $48 \mathrm{~h}$ with lopinavir (40 $\mu \mathrm{M}$ for $769-\mathrm{P}$ and $786-\mathrm{O}$ cells; $20 \mu \mathrm{M}$ for UMUC-3 and T-24 cells) with/without ritonavir (10 $\mu \mathrm{M}$ for $769-\mathrm{P}$ and $786-\mathrm{O}$ cells; $40 \mu \mathrm{M}$ for UMUC-3 and T-24 cells). Apoptotic cells were detected by annexin- $\mathrm{V}$ assay. To evaluate the expression of apoptosis-associated proteins, cells were treated for $48 \mathrm{~h}$ with lopinavir (20-40 $\mu \mathrm{M}$ for 769-P and 786-O cells; $10-20 \mu \mathrm{M}$ for UMUC-3 and T-24 cells) with/without ritonavir ( $10 \mu \mathrm{M}$ for $769-\mathrm{P}$ and $786-\mathrm{O}$ cells; $40 \mu \mathrm{M}$ for UMUC-3 and T-24 cells). Changes in the expression of cleaved PARP, NOXA, and survivin were assessed by western blotting.

Evaluating ER stress induction and mammalian target of rapamycin (mTOR) suppression by the lopinavir-ritonavir combination. Cells were treated for $48 \mathrm{~h}$ with lopinavir $(20-40 \mu \mathrm{M}$ for $769-\mathrm{P}$ and $786-$ O cells; $10-20 \mu \mathrm{M}$ for UMUC-3 and T-24 cells) with/without ritonavir (10 $\mu \mathrm{M}$ for 769-P and 786-O cells; $40 \mu \mathrm{M}$ for UMUC-3 and T-24 cells). Changes in the expression of GRP78, ERp44, AMPK, phosphorylated S6, S6, and 4EBP1 were assessed by western blotting.

Evaluating changes in the expression of TRAIL receptor by the lopinavir-ritonavir combination. Cells were treated with the combination $(40 \mu \mathrm{M}$ lopinavir and $10 \mu \mathrm{M}$ ritonavir for 769-P cells; $20 \mu \mathrm{M}$ lopinavir and $40 \mu \mathrm{M}$ ritonavir for UMUC-3 cells) for 12,24 , and $48 \mathrm{~h}$. Changes in the expression of the TRAIL receptor DR5 were evaluated by western blotting.

Evaluating sensitization of the cancer cells to TRAIL by the lopinavir-ritonavir combination. One day before treatment, cells for viability assay were placed in 96 -well culture plates $(5.0 \times 103$ cells/well) and cells for apoptosis assay were placed in 12-well culture plates $\left(1.0 \times 10^{5}\right.$ cells/well $)$. The cells were then treated with the combination $(40 \mu \mathrm{M}$ lopinavir and $10 \mu \mathrm{M}$ ritonavir for $769-\mathrm{P}$ cells; $20 \mu \mathrm{M}$ lopinavir and $40 \mu \mathrm{M}$ ritonavir for UMUC-3 cells) for $24 \mathrm{~h}$ before being cultured with $25 \mathrm{ng} / \mathrm{ml}$ TRAIL in addition for
Table I. Combination indices (CIs) for the combination of lopinavir and ritonavir against renal cancer cells and bladder cancer cells. $C I<1,=1$, and $>1$ indicates synergism, additive effect, and antagonism.

\begin{tabular}{lcccc}
\hline & & \multicolumn{3}{c}{ Lopinavir $(\mu \mathrm{M})$} \\
\cline { 3 - 5 } Cell line & Ritonavir $(\mu \mathrm{M})$ & 10 & 20 & 40 \\
\hline 769-P & 5 & 1.119 & 0.870 & 0.672 \\
& 10 & 1.271 & 0.838 & 0.739 \\
$786-\mathrm{O}$ & 5 & 0.693 & 0.697 & 0.075 \\
& 10 & 0.592 & 0.628 & 0.073 \\
& & 5 & 10 & 20 \\
\hline \multirow{2}{*}{ UMUC-3 } & 20 & 0.864 & 0.743 & 0.459 \\
& 40 & 0.709 & 0.541 & 0.223 \\
T-24 & 20 & 1.126 & 0.889 & 0.875 \\
& 40 & 0.712 & 0.597 & 0.679 \\
\hline
\end{tabular}

another $24 \mathrm{~h}$. Cell viability was measured by MTS assay $(\mathrm{n}=12)$ and apoptosis was evaluated by annexin- $\mathrm{V}$ assay.

Evaluating cycloheximide's effect on cytotoxicity and apoptosis induction by the lopinavir-ritonavir combination. One day before treatment, cells for viability assay were placed in 96-well culture plates $\left(5.0 \times 10^{3}\right.$ cells/well $)$ and cells for apoptosis assay were placed in 12 -well culture plates $\left(1.0 \times 10^{5}\right.$ cells/well $)$. The cells were then treated with the combination $(40 \mu \mathrm{M}$ lopinavir and $10 \mu \mathrm{M}$ ritonavir for 769-P and 786-O cells; $20 \mu \mathrm{M}$ lopinavir and $40 \mu \mathrm{M}$ ritonavir for UMUC-3 and T-24 cells) with or without $5 \mu \mathrm{g} / \mathrm{ml}$ cycloheximide for $48 \mathrm{~h}$. Cell viability was measured by MTS assay $(\mathrm{n}=12)$ and apoptosis was evaluated by annexin- $\mathrm{V}$ assay.

Evaluating cycloheximide's effect on ER stress induction, mTOR suppression, and increased DR5 expression by the lopinavirritonavir combination. Cells were treated for $48 \mathrm{~h}$ with the combination therapy ( $40 \mu \mathrm{M}$ lopinavir and $10 \mu \mathrm{M}$ ritonavir for 769 $\mathrm{P}$ and $786-\mathrm{O}$ cells; $20 \mu \mathrm{M}$ lopinavir and $40 \mu \mathrm{M}$ ritonavir for UMUC-3 and T-24 cells) with or without $5 \mu \mathrm{g} / \mathrm{ml}$ cycloheximide. Changes in the expression of GRP78, ERp44, AMPK, and DR5 were assessed by western blotting.

Cell viability assay. Cell viability was determined by MTS assay (CellTiter 96 Aqueous kit; Promega, Madison, WI, USA) following the manufacturer's protocol. Briefly, the medium was replaced with $20 \mu \mathrm{l}$ MTS solution in $100 \mu \mathrm{l}$ fresh medium after treatment. The plates were then incubated for 30-60 min and read in a microplate autoreader.

Annexin-V assay. Treated cells were washed with PBS, harvested by trypsinization, and stained with annexin $\mathrm{V}$ and 7-amino-actinomycin D (7-AAD) (Beckman Coulter, Marseille, France) according to the manufacturer's instructions. The cells were analyzed by using a flow cytometer and CellQuest Pro Software (BD Biosciences, San Jose, CA, USA). A total of 10,000 cells were counted. Data were obtained from three independent experiments. 


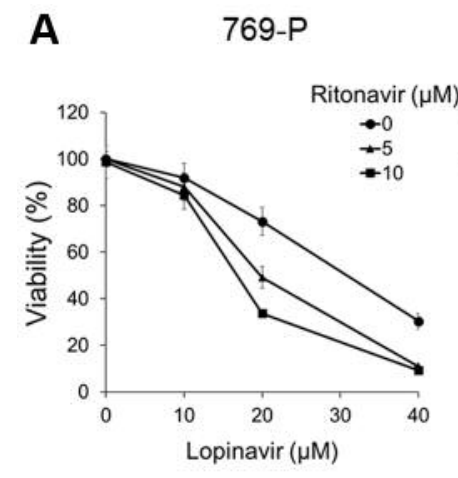

786-0

UMUC-3

T-24
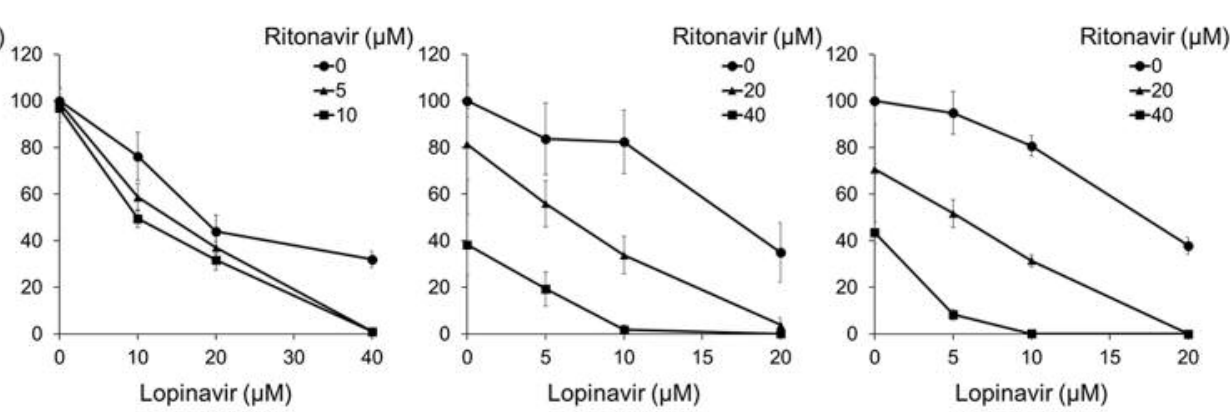

B
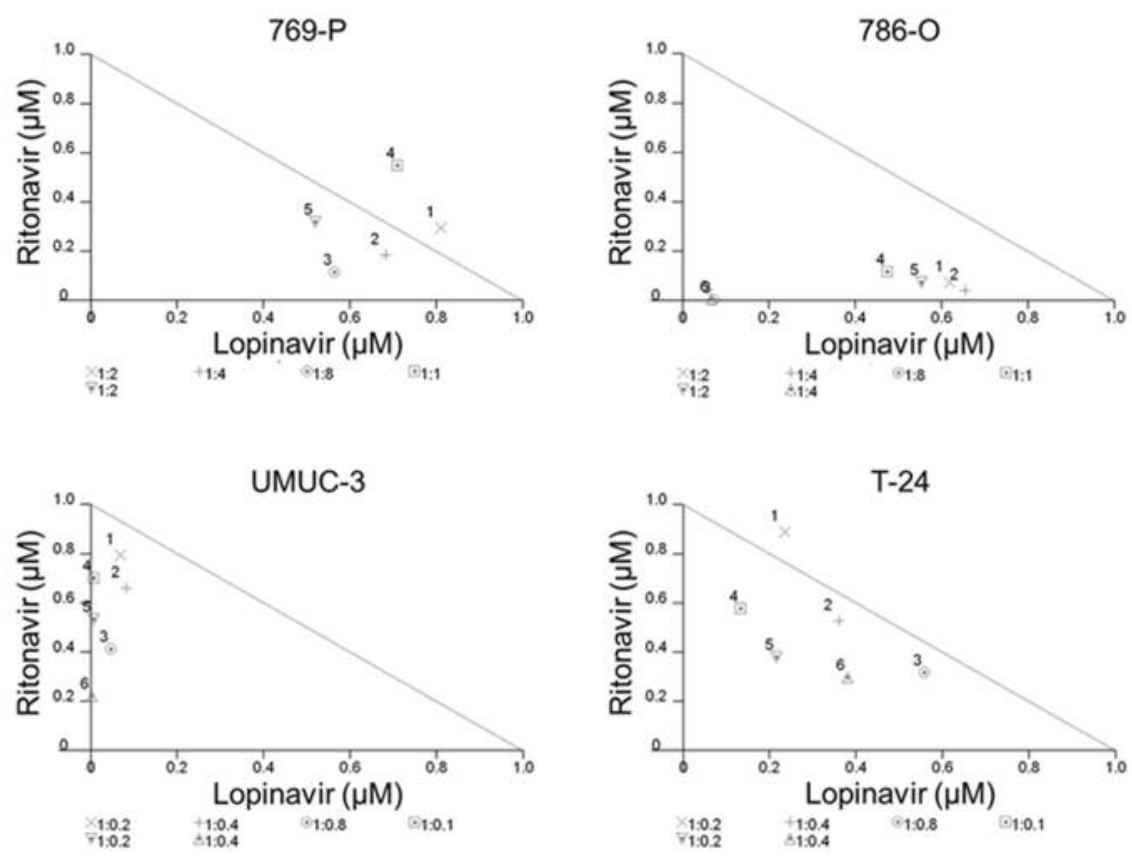

Figure 1. Continued

Western blotting. Treated cells were washed with PBS and whole cell lysates were obtained using radioimmunoprecipitation assay buffer. Equal amounts of proteins were separated by $12.5 \%$ sodium dodecyl sulfate-polyacrylamide gel electrophoresis and transferred to nitrocellulose membranes. The membranes were blocked by $5 \%$ skimmed milk, and they were incubated overnight with the primary antibodies described above. Then the protein was detected by reaction with secondary antibodies and staining with chemiluminescence solution with the ECL Plus system (GE Healthcare).

Statistical analysis. CalcuSyn software (Biosoft, Cambridge, UK) was used for calculating the combination indexes according to the method by Chou and Talalay (10). Statistical significance of observed differences between samples was evaluated using the Mann-Whitney $U$-test (JMP Pro14 software; SAS Institute, Cary, $\mathrm{NC}$, USA), and values of $p<0.05$ were considered to indicate a statistically significant difference.

\section{Results}

Co-administration of lopinavir and ritonavir synergistically inhibited the growth of cancer cells. According to the cell viability assay, the combination of lopinavir and ritonavir cooperatively inhibited the growth of the cancer cells (Figure 1A). The combined effect was synergistic under many of the treatment conditions (Figure 1B and Table I). Furthermore, the combination significantly inhibited the clonogenicity of the cancer cells (Figure 1C).

We next evaluated apoptosis induced by the combination. The combination increased the number of annexin- $V$ positive cells significantly (Figure 1D), increasing the expression of cleaved PARP and NOXA, and reducing the expression of the anti-apoptotic protein survivin (Figure 
C
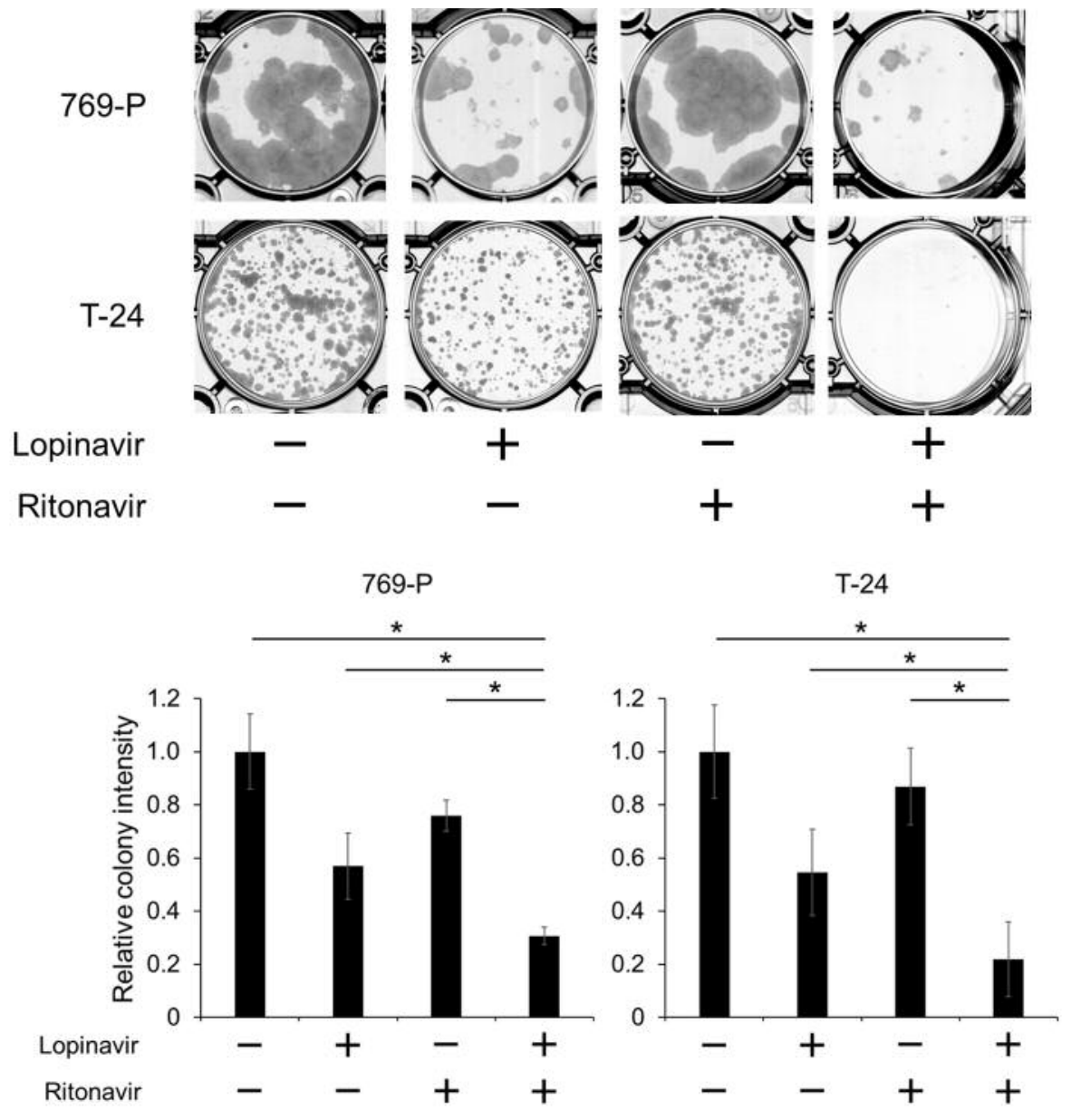

Figure 1. Continued

1E). Thus, the combination of lopinavir and ritonavir was shown to induce apoptosis.

The combination induced ER stress and increased the expression of AMPK, thereby suppressing the mTOR pathway. We then evaluated the changes in the expression of the ER stress markers GRP78 and ERp44 to see whether the combination induced ER stress. Lopinavir itself induced no or only moderate ER stress, and ritonavir enhanced this stress prominently (Figure 2A).

Previous studies demonstrated that ER stress induced AMPK expression in malignancies $(11,12)$. Furthermore, AMPK is known to act against cancer by suppressing the mTOR pathway (13). As expected, the combination indeed increased the expression of AMPK synergistically, inhibited the expression of 4EBP1, and also inhibited S6 phosphorylation (Figure 2B), suggesting that the combination actually inhibited the mTOR pathway by increasing the expression of AMPK.
Figure 1. Co-administration of lopinavir and ritonavir synergistically inhibited the growth of cancer cells. A: Cell viability assay. Cells were treated for $48 \mathrm{~h}$ with 5-40 $\mu \mathrm{M}$ lopinavir with/without 5-40 $\mu \mathrm{M}$ ritonavir, and cell viability was measured using MTS assay. Data are the mean $\pm S D, n=6$. B: Isobologram analysis for the combination of lopinavir and ritonavir. C: Colony formation assay. Cells were treated for $48 \mathrm{~h}$ with lopinavir $(40 \mu \mathrm{M}$ for 769-P cells and $20 \mu \mathrm{M}$ for $T-24$ cells) and/or ritonavir (10 $\mu M$ for 769-P cells and $40 \mu M$ for $T-24$ cells). The cells were then given fresh media and allowed to grow for 1-2 weeks. Bar graphs show the relative colony intensity. Data are the mean $\pm S D, n=3$. D: Annexin-V assay. Cells were treated for $48 \mathrm{~h}$ with lopinavir (40 $\mu \mathrm{M}$ for 769-P and 786-O cells; $20 \mu \mathrm{M}$ for UMUC-3 and T-24 cells) with/without ritonavir (10 $\mu M$ for 769-P and 786-O cells; $40 \mu M$ for UMUC-3 and T-24 cells). Apoptotic cells were detected by annexin-V assay using flow cytometry; 10,000 cells were counted. Data are the mean $\pm S D$ from three independent experiments. E: Western blotting for cleaved poly(ADP-ribose) polymerase (PARP), phorbol-12myristate-13-acetate-induced protein 1 (NOXA), and survivin. Cells were treated for $48 \mathrm{~h}$ with 10-40 $\mu \mathrm{M}$ lopinavir with/without 10-40 $\mu \mathrm{M}$ ritonavir. Actin was used for the loading control. Representative blots are shown. FITC: Fluorescein isothiocyanate; 7-AAD: 7-aminoactinomycin D. *Significantly different at $p=0.0495$. 
D
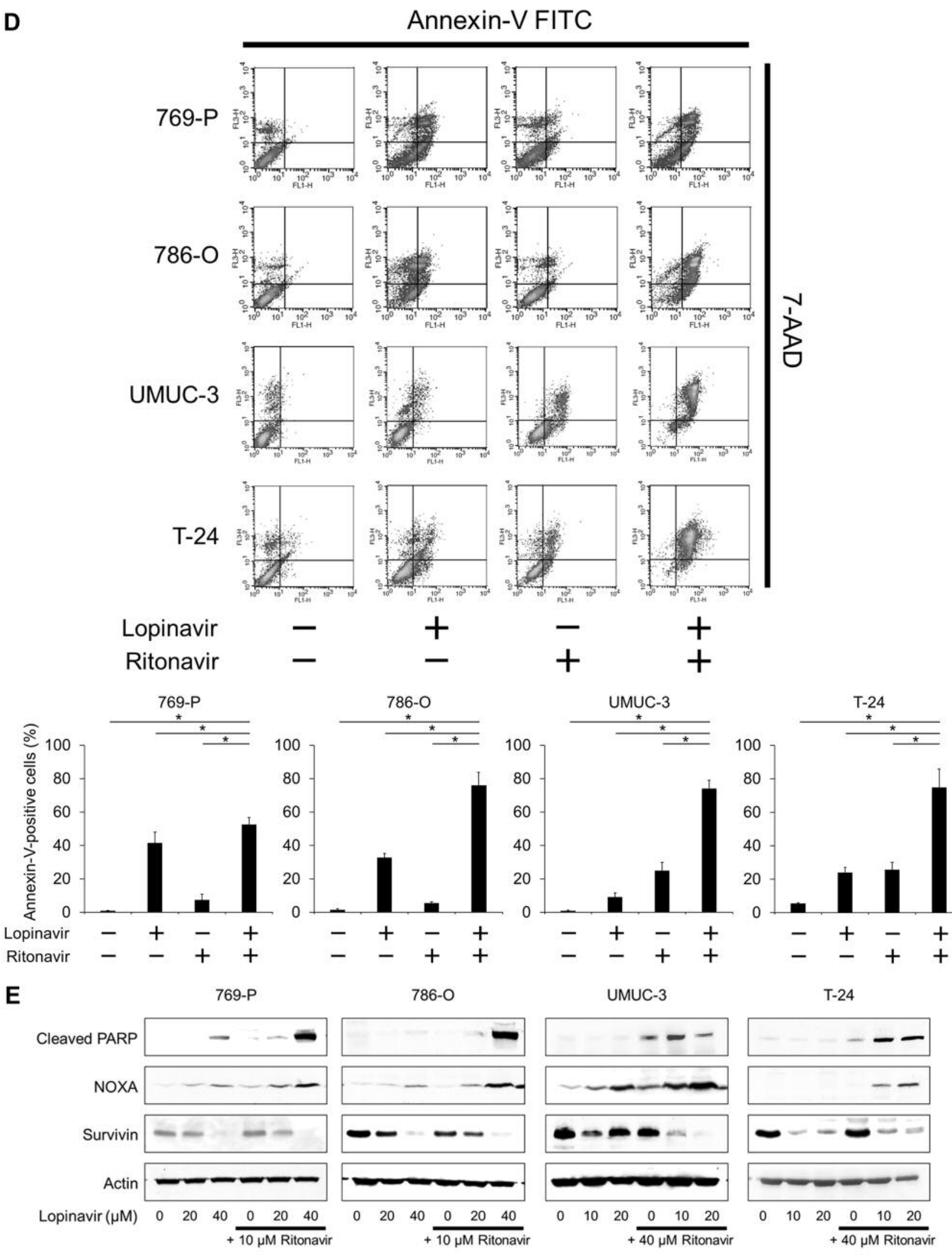
A

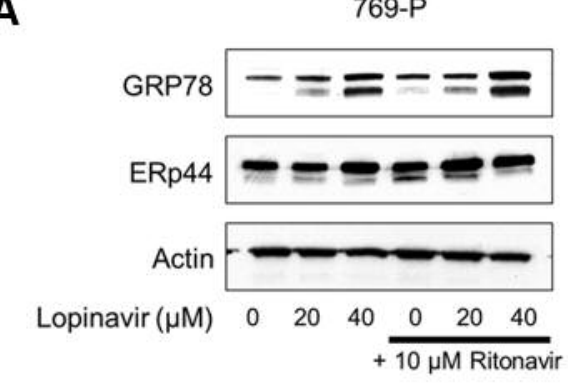

B

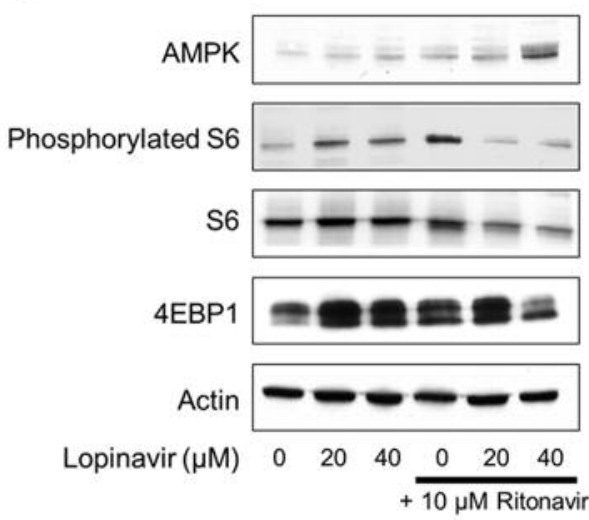

$786-0$

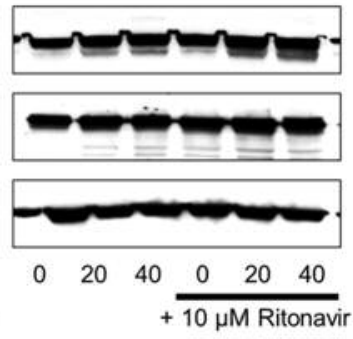

$786-0$
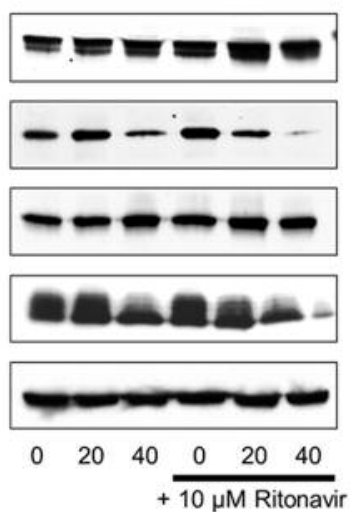

UMUC-3

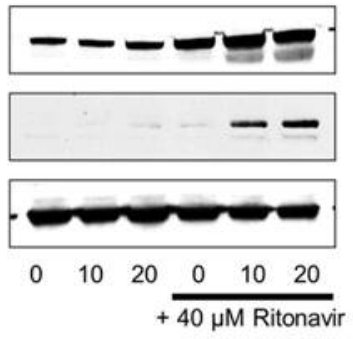

UMUC-3
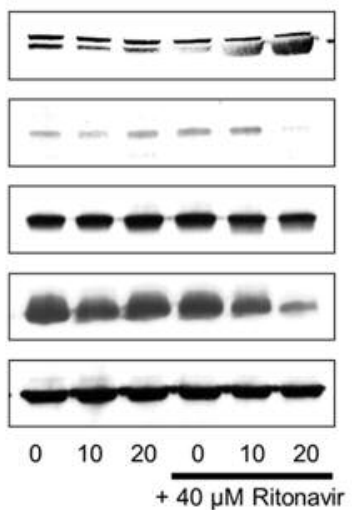

$\mathrm{T}-24$

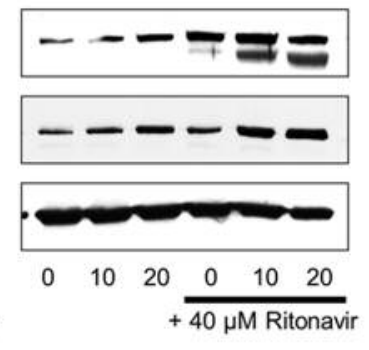

T-24
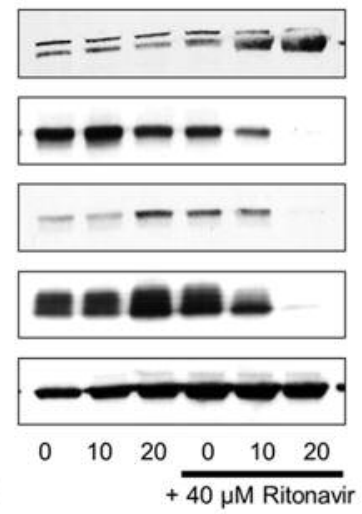

Figure 2. The combination of lopinavir and ritonavir induced endoplasmic reticulum (ER) stress and increased the expression of AMP-activated protein kinase (AMPK), thereby suppressing the mammalian target of rapamycin pathway. A: Western blotting for ER stress markers glucose-regulated protein 78 (GRP78) and endoplasmic reticulum resident protein 44 (ERp44). Cells were treated for $48 \mathrm{~h}$ with 10-40 $\mu \mathrm{M}$ lopinavir with/without 10-40 $\mu M$ ritonavir. Actin was used for the loading control. Representative blots are shown. B: Western blotting for AMPK, phosphorylated S6 ribosomal protein (phosphorylated S6), S6, and eukaryotic translation initiation factor 4E-binding protein 1 (4EBP1). Cells were treated for $48 \mathrm{~h}$ with $10-40$ $\mu \mathrm{M}$ lopinavir with/without 10-40 $\mu \mathrm{M}$ ritonavir. Actin was used for the loading control. Representative blots are shown.

The combination increased the expression of a TRAIL receptor and thereby sensitized cancer cells to TRAIL. ER stress induction reportedly increases the expression of TRAIL receptors $(11,14,15)$. Therefore, we next evaluated whether the combination increases the expression of a TRAIL receptor and thereby sensitizes the cancer cells to TRAIL. The combination induced ER stress and increased the expression of the TRAIL receptor DR5, with the expression being highest after $24 \mathrm{~h}$ of treatment (Figure 3A). As expected, the combination sensitized the cancer cells to TRAIL: The ability of TRAIL to exert cytotoxicity and induce apoptosis was significantly enhanced when the cells were pretreated with the combination for $24 \mathrm{~h}$ (Figures 3B and C).

ER stress induction played a pivotal role in the anticancer effect of the combination. We then evaluated the role of ER stress induction in the action of combination of lopinavir and ritonavir. The ER stress inhibitor cycloheximide (16) attenuated the cytotoxicity of the combination of lopinavir and ritonavir and impaired its ability to induce apoptosis (Figures 4A and B). Cycloheximide inhibited the combination-increased expression of GRP78 and ERp44, confirming that it indeed suppressed ER stress induction (Figure 4C). Cycloheximide also reduced the combinationincreased expression of AMPK and DR5. We inferred from cycloheximide effects that ER stress induction played a pivotal role in the combination's anticancer action.

\section{Discussion}

Inducing ER stress is an innovative approach to cancer therapy (7). HIV protease inhibitors are known to induce ER stress $(4,8,14,17,18)$, and in the present study we demonstrated that the lopinavir-ritonavir combination synergistically suppressed the growth of both renal cancer cells and bladder cancer cells by inducing ER stress.

Because ritonavir has been shown not only to increase the amount of unfolded proteins by inhibiting molecular chaperones (4) but also to act as a chemical booster $(3,4)$, 
A

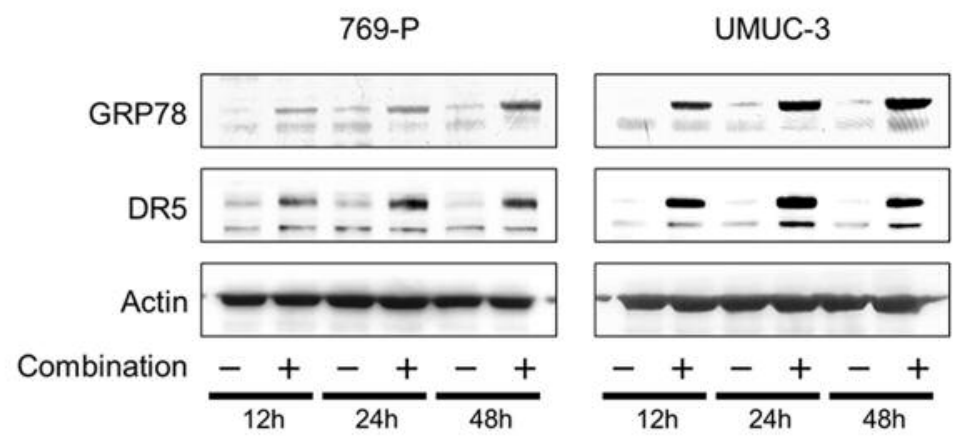

B

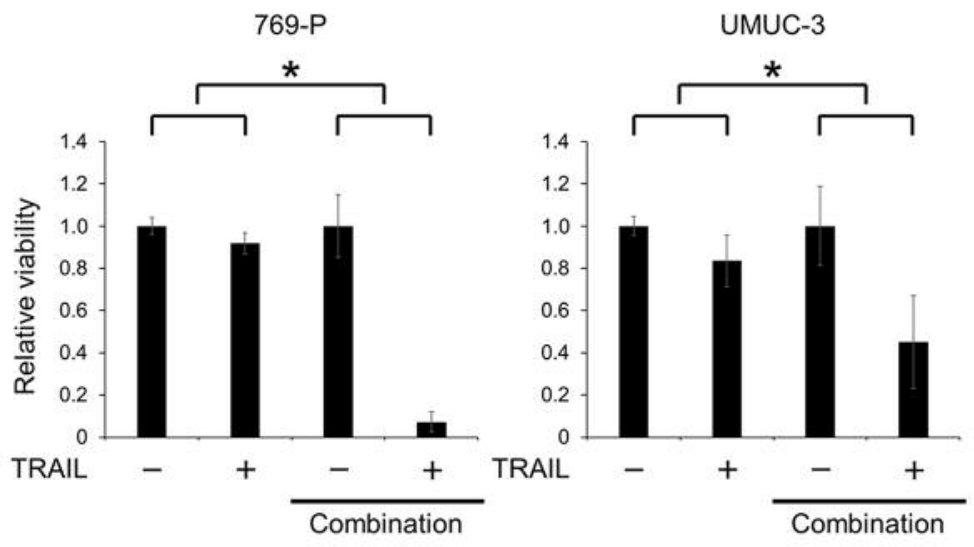

C

Annexin-V FITC

769-P
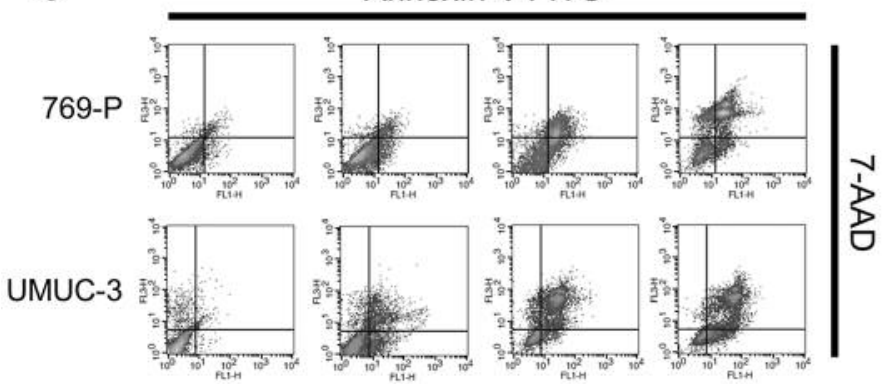

TRAIL

$+$
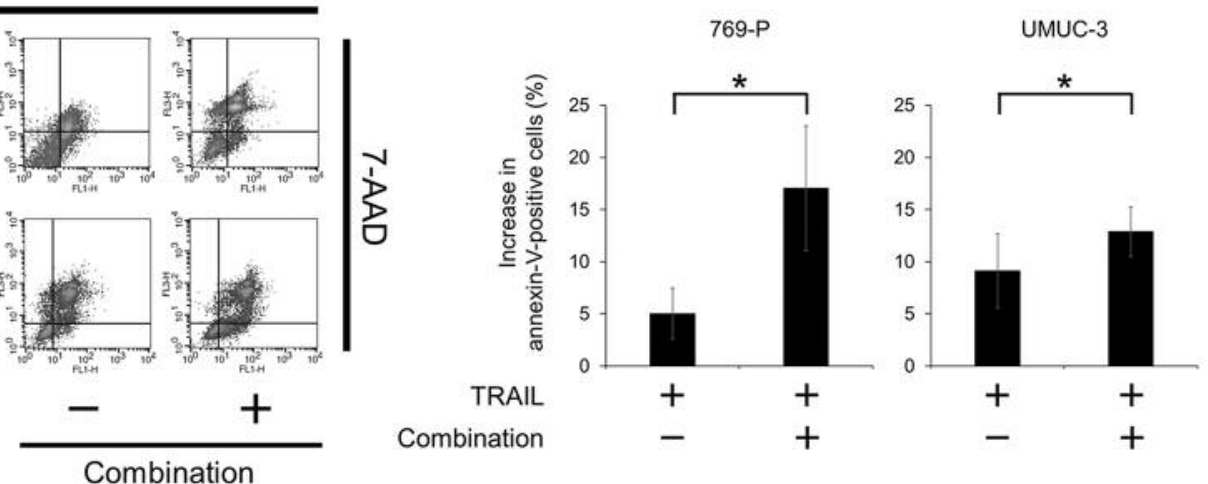

Figure 3. The combination of lopinavir and ritonavir increased the expression of a tumor necrosis factor-related apoptosis-inducing ligand (TRAIL) receptor and thereby sensitized cancer cells to TRAIL. A: Western blotting for glucose-regulated protein 78 (GRP78) and death receptor 5 (DR5). Cells were treated for 12-48 $\mathrm{h}$ with the combination of lopinavir and ritonavir. Actin was used for the loading control. Representative blots are shown. Combination, $40 \mu \mathrm{M}$ lopinavir and $10 \mu \mathrm{M}$ ritonavir for 769-P cells; $20 \mu \mathrm{M}$ lopinavir and $40 \mu \mathrm{M}$ ritonavir for UMUC-3 cells. B: MTS assay. Cells were cultured for $24 \mathrm{~h}$ in medium with or without the combination of lopinavir and ritonavir (40 $\mu M$ and $10 \mu M$, respectively for 769-P cells; $20 \mu \mathrm{M}$ and $40 \mu \mathrm{M}$, respectively for UMUC-3 cells). Then they were given $25 \mathrm{ng} / \mathrm{ml}$ TRAIL and incubated for another $24 \mathrm{~h}$. Bar graphs show the relative viability (the viability of the control cells and that of the cells treated with the combination alone were both set at 1). Data are the mean $\pm S D, n=12$. *Significantly different at $p=0.0001$. C: Annexin-V assay. Cells were cultured for 24 in medium with or without the combination of lopinavir and ritonavir. Then they were given $25 \mathrm{ng} / \mathrm{ml}$ TRAIL and incubated for another 24 h. Apoptotic cells were detected by annexin-V assay using flow cytometry; 10,000 cells were counted. Bar graphs show the increase in annexin-V positive cells by the addition of TRAIL. Data are expressed as mean $\pm S D$ from three independent experiments. FITC: Fluorescein isothiocyanate; 7-AAD: 7-amino-actinomycin D. *Significantly different at $p=0.0495$. 

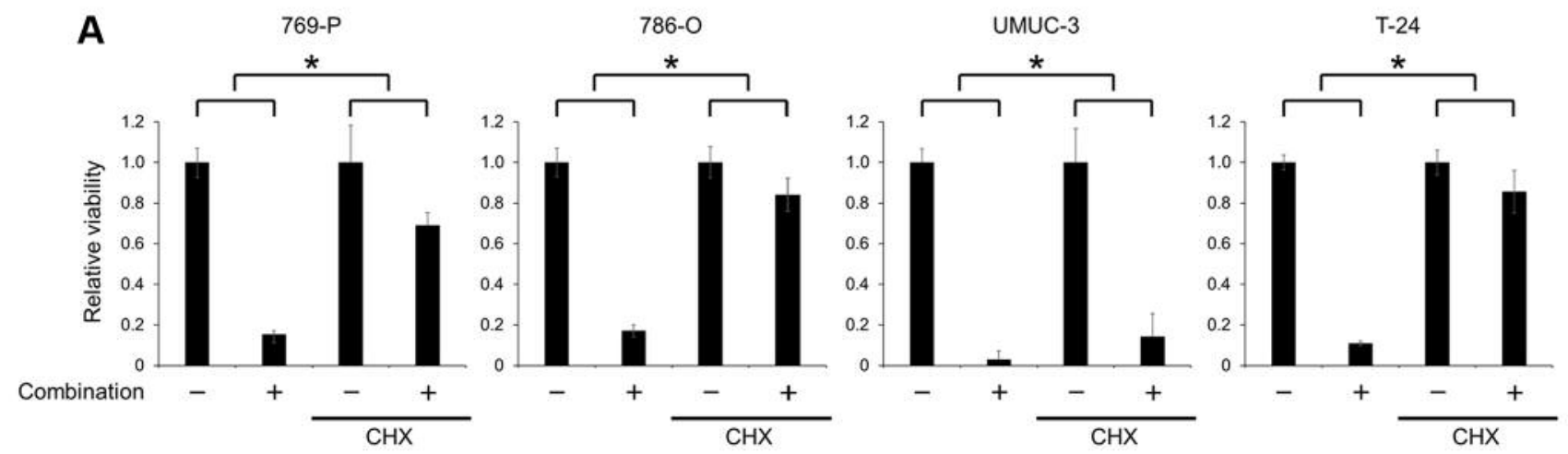

B
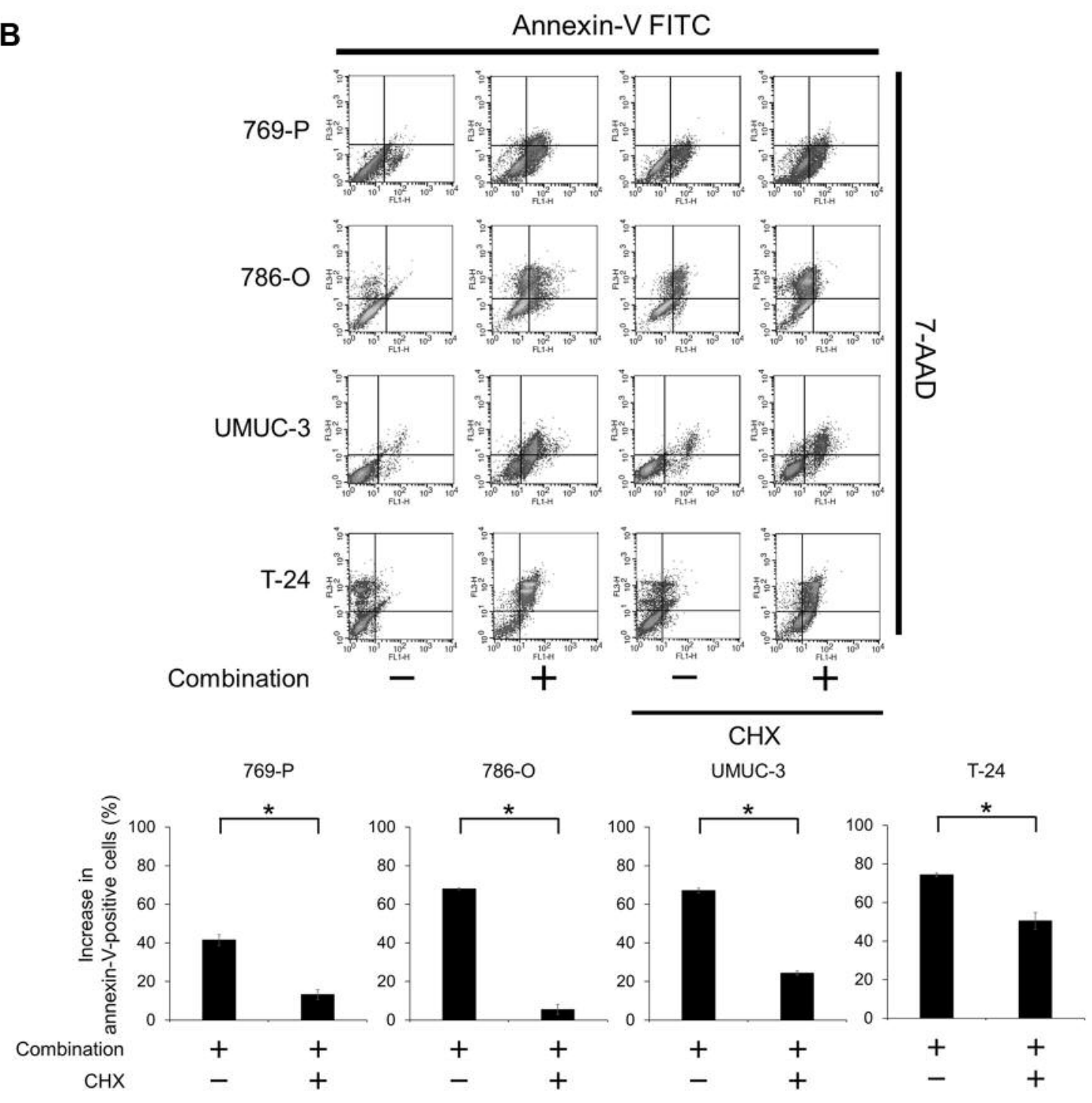

Figure 4. Continued 
C

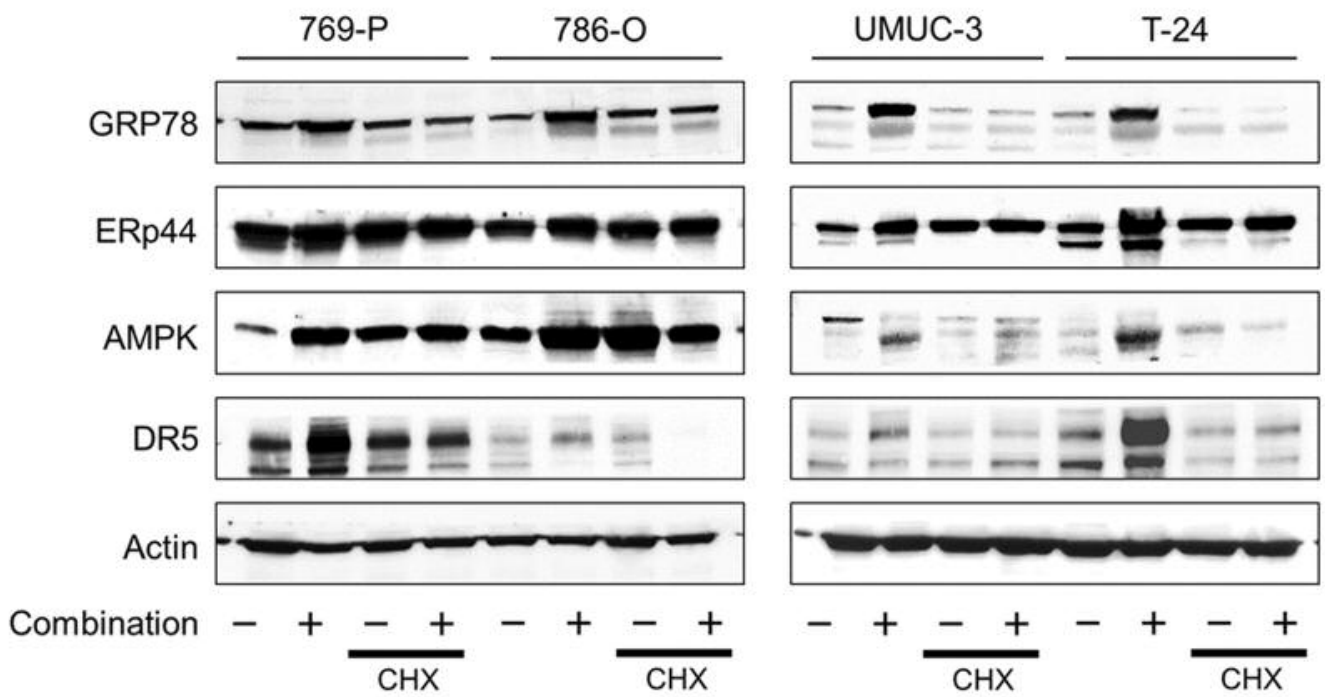

Figure 4. Endoplasmic reticulum (ER) stress induction played a pivotal role in the anticancer effect of the lopinavir-ritonavir combination. A: MTS assay. Cells were treated with the combination of lopinavir and ritonavir (40 $\mu \mathrm{M}$ and $10 \mu \mathrm{M}$, respectively for 769-P and 786-O cells; $20 \mu \mathrm{M}$ and $40 \mu \mathrm{M}$, respectively for UMUC-3 and T-24 cells) with or without $5 \mu \mathrm{g} / \mathrm{ml}$ cycloheximide (CHX) for 48 h. Bar graphs show the relative viability (the viability of the control cells and that of the cells treated with CHX alone were both set at 1). Data are the mean $\pm S D, n=12$. Significantly different at $* p=0.0001$. B: Annexin-V assay. Cells were treated with the combination of lopinavir and ritonavir with or without $5 \mu \mathrm{g} / \mathrm{ml}$ CHX for $48 \mathrm{~h}$. Apoptotic cells were detected by annexin-V assay using flow cytometry; 10,000 cells were counted. Bar graphs show the combination-increased annexin-V positive cells. Data are the mean $\pm S D$ from three independent experiments. FITC: Fluorescein isothiocyanate; 7-AAD: 7-aminoactinomycin D. Significantly different at $* p=0.0495$. C: Western blotting for glucose-regulated protein 78 (GRP78), endoplasmic reticulum resident protein 44 (ERp44), AMP-activated protein kinase (AMPK), and death receptor 5 (DR5). Cells were treated with the combination of lopinavir and ritonavir with or without $5 \mu \mathrm{g} / \mathrm{ml}$ CHX for $48 \mathrm{~h}$. Actin was used for the loading control. Representative blots are shown.

it is thought to be an ideal drug for inducing extensive ER stress in combination with other ER-stress-inducing agents (4, 19-21). Lopinavir, on the other hand, is also an HIV protease inhibitor and known as a strong ER stress inducer (8). We therefore believed co-administration of lopinavir and ritonavir would induce ER stress synergistically and thereby kill cancer cells effectively.

As postulated, the combination of lopinavir and ritonavir induced ER stress cooperatively. In addition, we found that the combination increased the expression of the mTOR inhibitor AMPK and inhibited the MTOR pathway. AMPK is an energy sensor activated by ATP depletion to promote cellular catabolism of nutrients (22). Recently, it has also been shown to control cancer cell growth by suppressing the mTOR pathway $(13,22,23)$. The mTOR pathway has been reported to play a key role in cell proliferation in both renal cancer and bladder cancer (24-26), therefore increasing AMPK expression would be a promising approach to killing those cancer cells. In the present study, we showed that AMPK expression in renal cancer cells and bladder cancer cells is increased by ER stress induced by the combination. ER stress induction can also trigger AMPK activation by decreasing cellular ATP levels $(27,28)$. Another important mechanism of AMPK activation is regulation of the AMPK- activating calcium/calmodulin-dependent kinase kinase (CaMKK)-beta by ER stress $(12,29,30)$. Furthermore, our previous studies revealed that ER stress induction is closely associated with AMPK activation $(31,32)$. Thus, ER stress is closely related to regulation of AMPK.

TRAIL, a member of the tissue necrosis factor family, induces apoptosis when it binds to TRAIL receptors $(33,34)$. Some studies reported that higher levels of intrinsic TRAIL expression are associated with more favorable response to surgical treatment and higher survival rates (35-37); increasing the susceptibility of cancer cells to TRAIL is thought to be an attractive approach to cancer therapy. Interestingly, we found that the combination of lopinavir and ritonavir triggered TRAIL-receptor-mediated cytotoxicity and apoptosis by increasing the expression of the TRAIL receptor DR5. Several studies have shown that ER stress induction increased the expression of TRAIL receptors, thereby sensitizing cancer cells to TRAIL and inducing TRAIL-mediated apoptosis $(11,14,38)$. Compatible with those studies, the increased DR5 expression we found was shown to be due to ER stress induced by the combination.

Because the lopinavir-ritonavir combination has widely been used for HIV treatment, it would be relatively easy to reposition it for other indications and use it to treat renal 
cancer and bladder cancer. Furthermore, the combination might be effective in killing cancer cells irrespective of cancer type because induction of ER stress is associated with the ubiquitin-proteasome pathway, a protein homeostasis mechanism essential for cell survival $(7,39)$. In fact, the combination effectively killed completely different types of cancer: renal cancer and bladder cancer. Its efficacy should therefore also be tested in other types of cancer.

To our knowledge, this is the first study showing that the lopinavir-ritonavir combination killed urological cancer cells by inducing ER stress and thereby increasing the expression of AMPK and DR5. The present study provides a framework for applying the combination to cancer treatment.

\section{Conflicts of Interest}

None.

\section{Authors' Contributions}

K.O., M.I., and A.S. designed the study. K.O. carried out all the experiments. K.O., M.I., T.A., and A.S. contributed to the interpretation of the results. K.O. wrote the article. A.S. supervised the study and edited the article. All Authors read and approved the final article.

\section{References}

1 Ashburn TT and Thor KB: Drug repositioning: identifying and developing new uses for existing drugs. Nat Rev Drug Discov 3(8): 673-683, 2004. PMID: 15286734. DOI: $10.1038 / \mathrm{nrd} 1468$

2 Nowak-Sliwinska P, Scapozza L and Altaba ARI: Drug repurposing in oncology: Compounds, pathways, phenotypes and computational approaches for colorectal cancer: Biochim Biophys Acta Rev Cancer 1871(2): 434-454, 2019. PMID: 31034926. DOI: 10.1016/j.bbcan.2019.04.005

3 Holmstock N, Annaert P and Augustijns P: Boosting of HIV protease inhibitors by ritonavir in the intestine: the relative role of cytochrome P450 and P-glycoprotein inhibition based on Caco-2 monolayers versus in situ intestinal perfusion in mice. Drug Metab Dispos 40(8): 1473-1477, 2012. PMID: 22550269. DOI: $10.1124 / \mathrm{dmd} .112 .044677$

4 Sato A: The human immunodeficiency virus protease inhibitor ritonavir is potentially active against urological malignancies. Onco Targets Ther 8: 761-768, 2015. PMID: 25914545. DOI: 10.2147/OTT.S79776

5 Walmsley S, Bernstein B, King M, Arribas J, Beall G, Ruane P, Johnson M, Johnson D, Lalonde R, Japour A, Brun S and Sun E; M98-863 Study Team: Lopinavir-ritonavir versus nelfinavir for the initial treatment of HIV infection. N Engl J Med 346(26): 2039-2046, 2002. PMID: 12087139. DOI: 10.1056/NEJMoa 012354

6 Cvetkovic RS and Goa KL: Lopinavir/ritonavir: a review of its use in the management of HIV infection. Drugs 63(8): 769-802, 2003. PMID: 12662125. DOI: 10.2165/00003495-200363080-00004

7 Liu Y and Ye Y: Proteostasis regulation at the endoplasmic reticulum: a new perturbation site for targeted cancer therapy.
Cell Res 21(6): 867-883, 2011. PMID: 21537343. DOI: 10.1038/ cr.2011.75

8 Taura M, Kariya R, Kudo E, Goto H, Iwawaki T, Amano M, Suico MA, Kai H, Mitsuya $\mathrm{H}$ and Okada S: Comparative analysis of ER stress response into HIV protease inhibitors: lopinavir but not darunavir induces potent ER stress response via ROS/JNK pathway. Free Radic Biol Med 65: 778-788, 2013. PMID: 23973637. DOI: 10.1016/j.freeradbiomed .2013.08.161

9 Guzmán C, Bagga M, Kaur A, Westermarck J and Abankwa D: ColonyArea: an ImageJ plugin to automatically quantify colony formation in clonogenic assays. PLoS One 9(3): e92444, 2014. PMID: 24647355. DOI: 10.1371/journal.pone.0092444

10 Chou TC: Drug combination studies and their synergy quantification using the Chou-Talalay method. Cancer Res 70(2): 440-446, 2010. PMID: 20068163. DOI: 10.1158/00085472.CAN-09-1947

11 Ma Z, Fan C, Yang Y, Di S, Hu W, Li T, Zhu Y, Han J, Xin Z, Wu G, Zhao J, Li X and Yan X: Thapsigargin sensitizes human esophageal cancer to TRAIL-induced apoptosis via AMPK activation. Sci Rep 6: 35196, 2016. PMID: 27731378. DOI: 10.1038/srep35196

12 Deshmukh RR and Dou QP: Proteasome inhibitors induce AMPK activation via CaMKK $\beta$ in human breast cancer cells. Breast Cancer Res Treat 153(1): 79-88, 2015. PMID: 26227473. DOI: $10.1007 / \mathrm{s} 10549-015-3512-2$

13 Faubert B, Vincent E, Poffenberger M and Jones RG: The AMPactivated protein kinase (AMPK) and cancer: many faces of a metabolic regulator. Cancer Lett 356: 165-170, 2015. PMID: 24486219. DOI: 10.1016/j.canlet.2014.01.018

14 Okubo K, Sato A, Isono M, Asano T and Asano T: Nelfinavir induces endoplasmic reticulum stress and sensitizes renal cancer cells to TRAIL. Anticancer Res 38(8): 4505-4514, 2018. PMID: 30061216. DOI: 10.21873/anticanres.12754

15 Yoon MJ, Kang YJ, Kim IY, Kim EH, Lee JA, Lim JH, Kwon TK and Choi KS: Monensin, a polyether ionophore antibiotic, overcomes TRAIL resistance in glioma cells via endoplasmic reticulum stress, DR5 upregulation and c-FLIP downregulation. Carcinogenesis 34(8): 1918-1928, 2013. PMID: 23615398. DOI: $10.1093 /$ carcin/bgt137

16 Ram BM and Ramakrishna G: Endoplasmic reticulum vacuolation and unfolded protein response leading to paraptosis like cell death in cyclosporine A treated cancer cervix cells is mediated by cyclophilin B inhibition. Biochim Biophys Acta 1843(11): 2497-2512, 2014. PMID: 25003316. DOI: 10.1016/ j.bbamcr.2014.06.020

17 Chow WA, Jiang C and Guan M: Anti-HIV drugs for cancer therapeutics: back to the future? Lancet Oncol 10(1): 61-71, 2009. PMID: 19111246. DOI: 10.1016/S1470-2045(08)70334-6

18 Pyrko P, Kardosh A, Wang W, Xiong W, Schönthal AH and Chen TC: HIV-1 protease inhibitors nelfinavir and atazanavir induce malignant glioma death by triggering endoplasmic reticulum stress. Cancer Res 67(22): 10920-10928, 2007. PMID: 18006 837. DOI: $10.1158 / 0008-5472 . C A N-07-0796$

19 Sato A, Asano T, Horiguchi A, Ito K, Sumitomo M and Asano $\mathrm{T}$ : Combination of suberoylanilide hydroxamic acid and ritonavir is effective against renal cancer cells. Urology 76(3): e7-13, 2010. PMID: 20630573. DOI: 10.1016/j.urology.2010.04.042

20 Isono M, Sato A, Okubo K, Asano T and Asano T: Ritonavir interacts with belinostat to cause endoplasmic reticulum stress and histone acetylation in renal cancer cells. Oncol Res 24(5): 
327-335, 2016. PMID: 27712589. DOI: $10.3727 / 096504016 \mathrm{X}$ 14666990347635

21 Sato A, Asano T, Okubo K, Isono M and Asano T: Ritonavir and ixazomib kill bladder cancer cells by causing ubiquitinated protein accumulation. Cancer Sci 108(6): 1194-1202, 2017. PMID: 28342223. DOI: $10.1111 /$ cas.13242

22 Wang W and Guan K: AMP-activated protein kinase and cancer. Acta Physiol (Oxf) 196(1): 55-63, 2009. PMID: 19243571. DOI: 10.1111/j.1748-1716.2009.01980.x

23 Jeon S and Hay N: The double-edged sword of AMPK signaling in cancer and its therapeutic implications. Arch Pharm Res 38(3): 346-357, 2015. PMID: 25575627. DOI: 10.1007/s12272015-0549-z

24 Brugarolas J: Renal cell carcinoma - molecular pathways and therapies. N Engl J Med 356(2): 185-187, 2007. PMID: 17215538. DOI: $10.1056 / \mathrm{NEJMe} 068263$

25 Thomas GV, Tran C, Mellinghoff IK, Welsbie DS, Chan E, Fueger B, Czernin J and Sawyers CL: Hypoxia-inducible factor determines sensitivity to inhibitors of mTOR in kidney cancer. Nat Med 12(1): 122-127, 2006. PMID: 16341243. DOI: 10.1038/nm1337

26 Chen M, Cassidy A, Gu J, Delclos GL, Zhen F, Yang H, Hildebrandt MA, Lin J, Ye Y, Chamberlain RM, Dinney CP and $\mathrm{Wu} \mathrm{X}$ : Genetic variations in PI3K-AKT-mTOR pathway and bladder cancer risk. Carcinogenesis 30(12): 2047-2052, 2009. PMID: 19875696. DOI: 10.1093/carcin/bgp258

27 Martinez Marignac VL, Smith S, Toban N, Bazile M and Aloyz $\mathrm{R}$ : Resistance to Dasatinib in primary chronic lymphocytic leukemia lymphocytes involves AMPK-mediated energetic reprogramming. Oncotarget 4(12): 2550-2566, 2013. PMID: 24334291. DOI: 10.18632 oncotarget.1508

28 Lin YC, Wu MH, Wei TT, Lin YC, Huang WC, Huang LY, Lin YT and Chen CC: Metformin sensitizes anticancer effect of dasatinib in head and neck squamous cell carcinoma cells through AMPK-dependent ER stress. Oncotarget 5(1): 298-308, 2014. PMID: 24457597. DOI: $10.18632 /$ oncotarget.1628

29 Woods A, Dickerson K, Heath R, Hong SP, Momcilovic M, Johnstone SR, Carlson $\mathrm{M}$ and Carling D: $\mathrm{Ca}^{2+/}$ calmodulindependent protein kinase kinase-beta acts upstream of AMPactivated protein kinase in mammalian cells. Cell Metab 2(1): 21 33, 2005. PMID: 16054096. DOI: 10.1016/j.cmet.2005.06.005

30 Hawley SA, Pan DA, Mustard KJ, Ross L, Bain J, Edelman AM, Frenguelli BG and Hardie DG: Calmodulin-dependent protein kinase kinase-beta is an alternative upstream kinase for AMPactivated protein kinase. Cell Metab 2(1): 9-19, 2005. PMID: 16054095. DOI: 10.1016/j.cmet.2005.05.009

31 Okubo K, Isono M, Asano T and Sato A: Panobinostat and nelfinavir inhibit renal cancer growth by inducing endoplasmic reticulum stress. Anticancer Res 38(10): 5615-5626, 2018. PMID: 30275179. DOI: 10.21873/anticanres.12896

32 Sato A, Asano T, Okubo K, Isono M and Asano T: Nelfinavir and ritonavir kill bladder cancer cells synergistically by inducing endoplasmic reticulum stress. Oncol Res 26(2): 323-332, 2018. PMID: 28560953. DOI: 10.3727/096504017X14957929842972
33 Graves JD, Kordich JJ, Huang TH, Piasecki J, Bush TL, Sullivan T, Foltz IN, Chang W, Douangpanya H, Dang T, O'Neill JW, Mallari R, Zhao X, Branstetter DG, Rossi JM, Long AM, Huang $\mathrm{X}$ and Holland PM: Apo2L/TRAIL and the death receptor 5 agonist antibody AMG 655 cooperate to promote receptor clustering and antitumor activity. Cancer Cell 26(2): 177-189, 2014. PMID: 25043603. DOI: 10.1016/j.ccr.2014.04.028

$34 \mathrm{Su}$ RY, Chao Y, Chen TY, Huang DY and Lin WW: 5Aminoimidazole-4-carboxamide riboside sensitizes TRAIL- and $\mathrm{TNF}\{$ alpha $\}$-induced cytotoxicity in colon cancer cells through AMP-activated protein kinase signaling. Mol Cancer Ther 6(5): 1562-1571, 2007. PMID: 17513605. DOI: 10.1158/15357163.MCT-06-0800

35 Krieg A, Mersch S, Wolf N, Stoecklein NH, Verde PE, am Esch JS 2nd, Heikaus S, Gabbert HE, Knoefel WT and Mahotka C: Expression of TRAIL-splice variants in gastric carcinomas: identification of TRAIL- $\gamma$ as a prognostic marker. BMC Cancer 13: 384, 2013. PMID: 23937794. DOI: 10.1186/1471-2407-13384

36 Anees M, Horak P, El-Gazzar A, Susani M, Heinze G, Perco P, Loda M, Lis R, Krainer M and Oh WK: Recurrence-free survival in prostate cancer is related to increased stromal TRAIL expression. Cancer 117(6): 1172-1182, 2011. PMID: 21381010. DOI: $10.1002 / \mathrm{cncr} .25504$

37 Li Y, Jin X, Li J, Jin X, Yu J, Sun X, Chu Y, Xu C, Li X, Wang $\mathrm{X}$, Kakehi $\mathrm{Y}$ and Wu X: Expression of TRAIL, DR4, and DR5 in bladder cancer: correlation with response to adjuvant therapy and implications of prognosis. Urology 79(4): e7-15, 2012. PMID: 22244504. DOI: 10.1016/j.urology.2011.11.011

38 Chen LH, Jiang CC, Kiejda KA, Wang YF, Thorne RF, Zhang XD and Hersey P: Thapsigargin sensitizes human melanoma cells to TRAIL-induced apoptosis by up-regulation of TRAIL-R2 through the unfolded protein response. Carcinogenesis 28(11): 2328-2336, 2007. PMID: 17652336 . DOI: $10.1093 /$ carcin/bgm173

39 Mimnaugh EG, Xu W, Vos M, Yuan X, Isaacs JS, Bisht KS, Gius D and Neckers L: Simultaneous inhibition of HSP 90 and the proteasome promotes protein ubiquitination, causes endoplasmic reticulum-derived cytosolic vacuolization, and enhances antitumor activity. Mol Cancer Ther 3(5): 551-566, 2004. PMID: 15141013.
Received August 30, 2019

Revised October 2, 2019

Accepted October 4, 2019 